\title{
NUMERICAL INVESTIGATION ON CYCLIC BEHAVIOR OF RING-BEAM CONNECTION TO GANGUE CONCRETE FILLED STEEL TUBULAR COLUMNS
}

\author{
Chen Fang ${ }^{1}$, Guo-Chang $\mathrm{Li}^{2}$ and Lei Zhang $3,4, *$ \\ ${ }^{1}$ Midwest Roadside Safety Facility, University of Nebraska-Lincoln, Lincoln, Nebraska 68583, USA \\ ${ }^{2}$ Professor, Shenyang Jianzhu University, Shenyang, Liaoning 110168, China \\ ${ }^{3}$ Lecturer, School of Civil Engineering and Architecture, Jiangsu University of Science and Technology, Zhenjiang, Jiangsu 212100, China \\ ${ }^{4}$ Postdoctor, Institute of Geotechnical Engineering, Nanjing Tech University, Nanjing, Jiangsu 211816, China \\ *(Corresponding author: E-mail: lei.zhang@just.edu.cn)
}

\section{A B S T R A C T}

As a promising composite structure, gangue concrete filled steel tubular (GCFST) column exhibites favarable characteristics including high strength and economic efficiency. This paper conducted numerical investiagations on structural behavior of a ring-beam connection to GCFST column with concrete beam under cyclic loading. Furthermore, finite element models of column-beam connections were developed using ABAQUS and validated against full-scale experimental tests to identify accuracy of selected modeling approaches. Using these validated models, stress distribution of each component was examined to study the force-transferring mechanism among the components and failure modes of the ring-beam connection. Research study indicated that the ring-beam connection showed a reasonable force-transferring mechanism under cyclic loading and the remarkable earthquake-resistant performance with high capacity and acceptable ductility. Finally, parametric studies were performed to assess the influences of beam-to-column stiffness ratio,steel ratio, axial load level, and concrete compressive strength on connection cyclic behaviors. Parametric studies provided some suggestions and references for the application of the ring-beam connection in various engineering projects.
ART I CLE H I S T O RY

$\begin{array}{ll}\text { Received: } & \text { 10 July } 2020 \\ \text { Revised: } & \text { 26 April } 2021 \\ \text { Accepted: } & 1 \text { May } 2021\end{array}$

Accepted: $\quad 1$ May 2021

\section{KE Y W O R D S}

Column-beam connection

Gangue concrete filled steel tube;

Cyclic behavior;

Finite element modeling;

Ring beam

Copyright $(2021$ by The Hong Kong Institute of Steel Construction. All rights reserved.

\section{Introduction}

Concrete-filled steel tubular (CFST) structure has been widely utilized as structural elements in the large-span bridges and high-rise building due to its high strength and stiffness [1]. A new gangue concrete filled steel tubular (GCFST) members is developed by replacing regular concrete with gangue concrete filled in steel tube [2]. Research studies indicate that the GCFST column with a ductile behavior provides high performance under various loading conditions. Compared to normal CFST column, the GCFST column demonstrates several merits [3, 4]: (i) The low density of the gangue concrete results in the reduction of weight (at least 20\%) for reinforced concrete (RC) building compared to the normal concrete [5]; (ii) The gangue concrete has better lateral deformation characteristic than the regular concrete to effectively increase tube confinement effect and improve the load bearing capacity of GCFST member [6]; (iii) The use of gangue concrete in the engineering projects is a beneficial method that reduces the environmental pollution and achieves the favorable economic and social benefits [7].

During an earthquake event, the column-beam connection is a critical component that provides a large strength to the entire building and ensures building serviceability. The column-beam connection is designed to have a large strength that allows the forces to transfer into the column with the formation of a plastic hinge in the RC frame beam. In this manner, beams could fail prior to column, which avoids the occurrence of progressive collapse in the building due to cascade effect initiated the failure of low-level columns. Consequently, the stability and safety of a RC building depend on the behavior of column-beam connection under an earthquake event. Experimental and numerical research studies have been completed to investigate the behavior of column-beam connection to the CFST column. Han and $\mathrm{Li}$ [8] experimentally examined dynamic behavior of connection between circular CFST column and steel beams under reversed cyclic loading. Pucinotti et al. [9] developed a welded column-beam connection for the CFST column and experimentally investigated its seismic performance. Results demonstrated the acceptable performance for the seismic design requirements. Chen et al. [10] conducted experimental and numerical studies on dynamic response of a through-beam connection between CFST column and RC beam when subjected to cyclic loads. Parametric studies were performed to evaluate effects of reinforcement ratio between the ring beam and frame beam and axial load at the column top on the connection performance. Li et al. [3] developed a rebar-penetrated connection to GCFST column and conducted experimental test and finite element analysis to examine the connection seismic performance. Ding et al. [11] performed experimental and numerical investigations on earthquake-resistance behavior of a non-throughcore connection between RC beams and CFST column in terms of strain, ductility, and stiffness degradation. Limited studies have been published that investigated the cyclic-loaded response of the connection to GCFST column. Research studies on the connection to the GCFST column would provide useful design information for its potential application in engineering projects.

This paper conducted numerical investigations that evaluated the performance of a ring-beam connection between GCFST column and RC beam under cyclic loading. This ring-beam connection consisted of four primary components including the GCFST column, frame beams, ring beam and shear ring welded in steel tube. Fig. 1 shows diagram of typical ring-beam connection to the GCFST column. Detailed finite element models of the ring-beam connections were developed using ABAQUS. Numerical results were validated against tested results to evalute the accuracy of the developed model. The connection response to cyclic load was then examined to analyze the stress distribution and failure mode in each component of the ring-beam connection. Finally, extensive parametric studies were conducted to assess effects of critical parameters on cyclic loaded connection behavior. These studied parameters included the axial load level, steel ratio, concrete compressive strength, ring beam width, column slenderness ratio, and column-beam stiffness ratio.

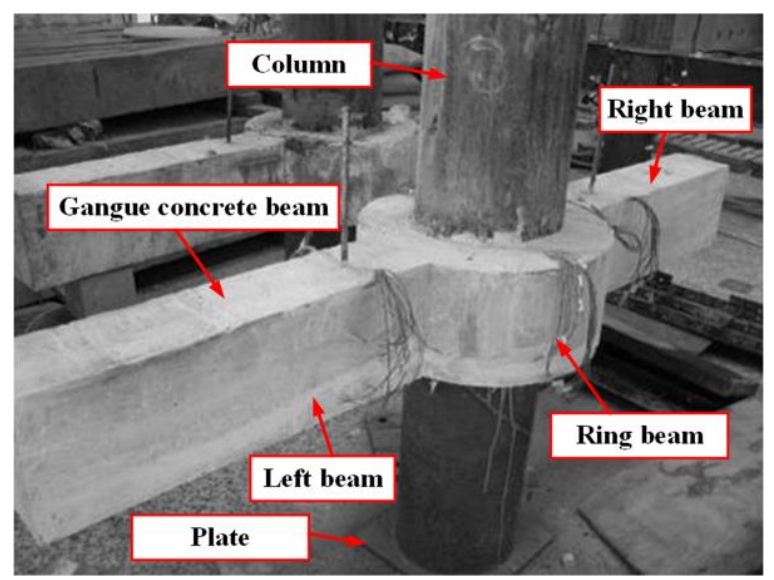

Fig. 1 Ring-beam connection to GCFST column

\section{Finite element modeling}

\subsection{Material model}

To reasonably represent concrete stiffness deterioration, ABAQUS's concrete plastic damage model was utilzed to simulate the dynamic response of 
the concrete [12]. Given the steel tube confinement effect, the constitutive model for the light-aggregate concrete filled in tube developed by Fu et al. [13] was used to represent the behavior of core concrete in the compression zone. The light-aggregate concrete constitutive developed by Zhang et al. [14] was utilized to simulate the concrete response under dynamic loading for the unconfined gangue concrete in the compression zone, as shown in Fig. 2. These concrete constitutive models demonstrated their abilities to reasonably represent the experimental results and ensure computation convergency. The gangue concrete in the tension zone was modeled using the energy fracture criterion considering the concrete softening characteristics [15]. The concrete fracture energy $\left(G_{f}\right)$ is formulated in the Eq. (1).

$G_{f}=a\left(\frac{f_{c}^{\prime}}{10}\right)^{0.7} \times 10^{-3}$

where $a=1.25 d_{\max }+10$ (unit: $\mathrm{mm}$ ); $d_{\max }$ is the maximum size of the concrete aggregate; and $f_{c}^{\prime}$ is the compressive strength of the concrete. The concrete accumulative damage was modeled using a damage variable $\left(d_{c}\right)$ with a fracture energy-crack displacement curve as shown in Eq. (2).

$$
d_{c}=1-\frac{\sigma_{c}+n_{c} \sigma_{c u}}{E_{c}\left(\frac{n_{c} \sigma_{c u}}{E_{c}}+\varepsilon_{c}\right)}
$$

where $\sigma_{c}$ is compressive stress; $\sigma_{c u}$ is ultimate compressive strain; $E_{c}$ is concrete elastic stiffness; $\varepsilon_{c}$ is compressive strain; and $n_{c}$ is a constant coefficient under compression and is larger than 0 . According to previous research studies [8] and computation trials, $n_{c}$ was taken to 1 for unconfined gangue concrete in the RC beam and 2 for the steel tube confined gangue concrete under compression. The default of compressive stiffness recovery factor $\left(w_{c}=1\right)$ was defined in numerical simulation.

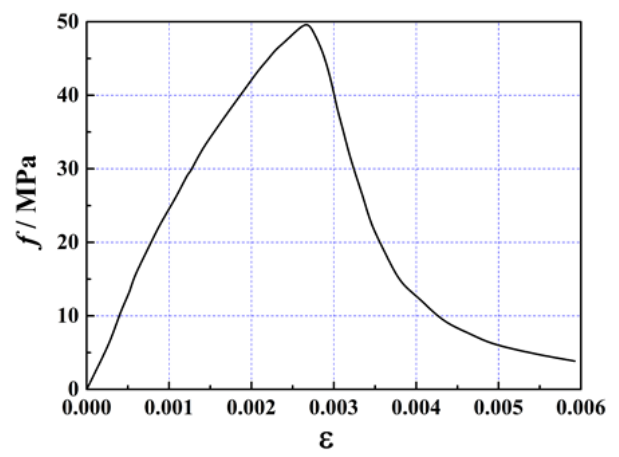

Fig. 2 Constitutive model of confined gangue concrete

A steel hysteretic constitutive model was employed to simualte the cyclicloading response of steel tube [16]. ABAQUS's kinematic hardening model which involves a von Mises yield surface and consideres an associate plastic flow rule for the steel properties [17] was also utilized for the steel to consider the Bauschinger effects on the connection cyclic behaviors [18]. Based on research studies and computation trails, the reinforcement response to cyclic load was modeled using a double-linear constitutive model that considers bearing capacity deterioration (USTEEL02) developed by Tsinghua University [19]. This model (USTEEL02) has demonstrated its ability to reasonably replicate the experimental results for RC structures and accurately simulated the slip bond between reinforcing bar and its surrounding concrete.

\subsection{Mesh and Element}

The concrete and rigid plate were modeled using 8-node, reducedintegration, solid element and the mapping self-customized mesh technique in ABAQUS. The steel tube was simulated using 4-node, reduced-integration, shell element and considering Simpson's rule through the cross-section of shell element. Reinforcement embedded in the gangue concrete was modeled using two-node truss element. The embedded region model in ABAQUS was used to couple the reinforcement into its surrounding concrete. Fig. 3 shows the developed numerical model of the ring-beam connection. The accuracy and efficiency of developed numerical model always depends on the mesh density for each component. In order to achieve a balance between the accurate result and computation speed, the mesh size in the central portions of the connection was refined, with the increased mesh size for the remaining portions. The mesh sizes in the steel tube and core gangue concrete was identical to improve computation convergency.

\subsection{Contact and boundary conditions}

For GCFST column, the interaction between steel tube and confined gangue concrete consists of interfacial contact and slip bond. The interfacial contact in the normal direction was modeled using a hard contact model to fully transfer the tube-concrete contact stress. For the slip bond in the tangential direction, the penalty-based friction contact model was selected using a Mohr-Coulomb friction formulation [20], with a friction coefficient of 0.6 [15]. In order to transfer uniformly the normal force at the column top and reduce effects of boundary conditions, both plates at the column top and bottom were simulated as the elastic plates with large stiffness. The end plate elastic modulus was $1 \times 10^{12} \mathrm{MPa}$, and the Poisson's ratio was 0.0001 . The contact between steel tube and end plates was modeled using a solid-to-shell coupling model, and a hard contact was used to represent the core concrete - end plate contact. In the experimental test, the hinged boundary condition was assumed at the top and the bottom of the GCFST column. In the numerical model, the column bottom was constrained using $\mathrm{UR} 1=\mathrm{UR} 3=0$ and $\mathrm{U} 1=\mathrm{U} 2=\mathrm{U} 3=0$, with a hinged boundary condition at the top. The cyclic load in a form of a displacement was placed at both ends of frame beams, as shown in Fig. 4, in which $P_{y}$ is the estimated bearing capacity at yielding of the ring-beam connection. During numerical simulation, a constant axial load $\left(N_{0}\right)$ was applied at the column top.

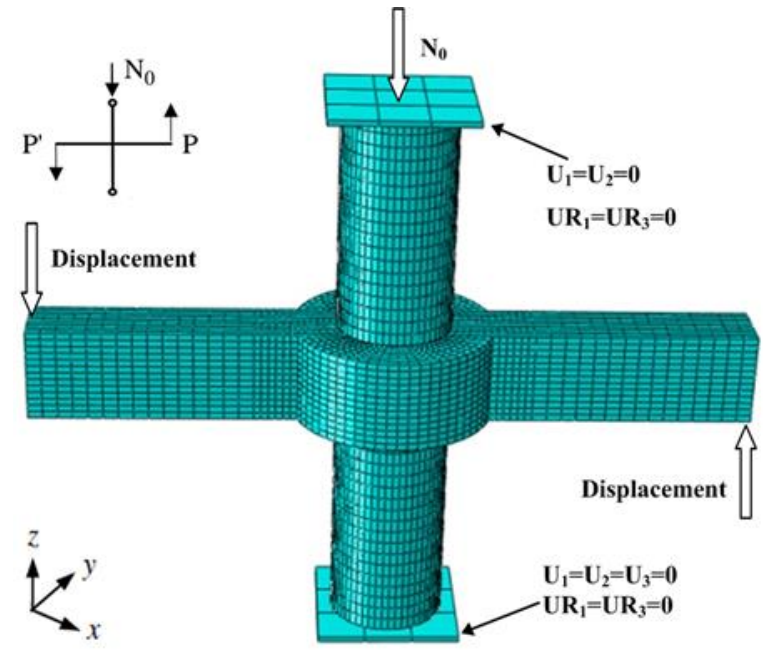

(a) Connection model (ube and concrete)

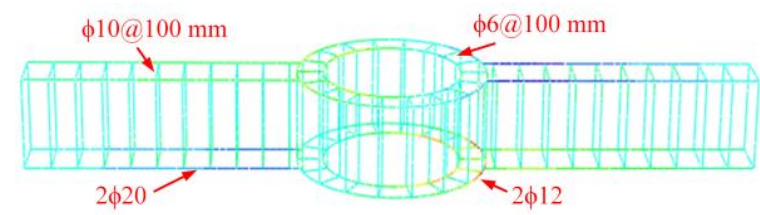

(b) Reinforcement details

Fig. 3 Ring-beam connection numerical model

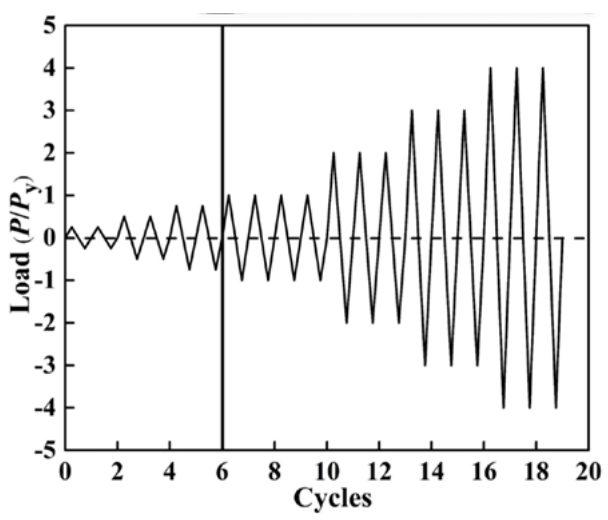

Fig. 4 Cyclic loading 


\subsection{Validation studies}

Table 1

Dimensions of tested and modeled specimens

\begin{tabular}{ccccccccccc}
\hline Specimen & $\begin{array}{c}L \\
(\mathrm{~m})\end{array}$ & $\begin{array}{c}D \times t \\
(\mathrm{~mm})\end{array}$ & $\begin{array}{c}b_{0} \\
(\mathrm{~m})\end{array}$ & $\alpha$ & $\lambda$ & $\begin{array}{c}l \\
(\mathrm{~m})\end{array}$ & $k$ & $\begin{array}{c}f_{c, b}^{\prime} \\
(\mathrm{MPa})\end{array}$ & $\begin{array}{c}f^{\prime}{ }_{c, c} \\
(\mathrm{MPa})\end{array}$ & $n$ \\
\hline JH-E-B & 1.5 & $325 \times 6$ & 0.12 & 0.078 & 36 & 1 & 0.853 & 30 & 30 & 0.6 \\
JH-E-Z & 1.5 & $325 \times 6$ & 0.12 & 0.078 & 36 & 2 & 0.853 & 30 & 30 & 0.6 \\
JH-A-B & 1.5 & $325 \times 6$ & 0.12 & 0.078 & 36 & 1 & 0.853 & 30 & 30 & 0.6 \\
JH-A-Z & 1.5 & $325 \times 6$ & 0.12 & 0.078 & 36 & 2 & 0.853 & 30 & 30 & 0.6 \\
\hline
\end{tabular}

Experimental studies were completed on two specimens with an interior connection having two frame beams (JH-E-Z) and an exterior connection having one frame beam (JH-E-B) subjected to a constant axial load at the column top and cyclic loads at the beam ends. Numerical models corresponding to these specimens were developed and validated by the comprisons between simulated and tested results. In the test, the column was designed as a circular gangue concrete filled steel tubular column with a diameter of $325 \mathrm{~mm}$. All beams having the cross-sectional dimensions of $180 \times 250 \mathrm{~mm}$ were reinforced by $2 \phi 20$ longitudinal bars and $\phi 10$ hoops spaced at $100 \mathrm{~mm}$. The vertical height of the column was $1500 \mathrm{~mm}$. The ring beam had a cross-sectional dimension of $120 \times 250 \mathrm{~mm}$ and $2 \phi 12$ longitudinal bars, with $\phi 6$ hoops spaced at $100 \mathrm{~mm}$. The axial load ratio of 0.6 was designed at the column top during testing. Two numerical models that corresponded to the tested specimens were developed using ABAQUS, with interior connection referred to as JH-A-Z and exterior connection as JH-A-B

Table 1 lists geomitries and properties of tested and modeled specimens. In the table, $L$ is the column height; $D$ is the column diameter; $t$ is the tube thickness; $b_{0}$ is the width of ring beam; $l$ is the beam length; $\alpha$ is the steel ratio ( $A_{S C} / A_{C C}$, where $A_{S C}$ and $A_{C C}$ are the cross-sectional areas of GCFST column and core concrete, respectively); $\lambda$ is the slenderness ratio of column, defined as $4 l_{c} I D$, where $l_{c}$ is the calculated column height; $k$ is the beam-to-column bending stiffness ratio, which is calculated as the ratio of beam stiffness to column stiffness; $f_{c, b}^{\prime}$ is the unconfined concrete compressive strength for the frame beam; $f_{c, c}^{\prime}$ is the confined concrete compressive strength for the GCFST column; $n$ is the axial load ratio, defined as $N_{0} / N_{u}$, where $N_{0}$ is the axial load applied at the column top, and $N_{u}$ is the plastic axial capacity of the GCFST column calculated by CECS28-2012 [21].

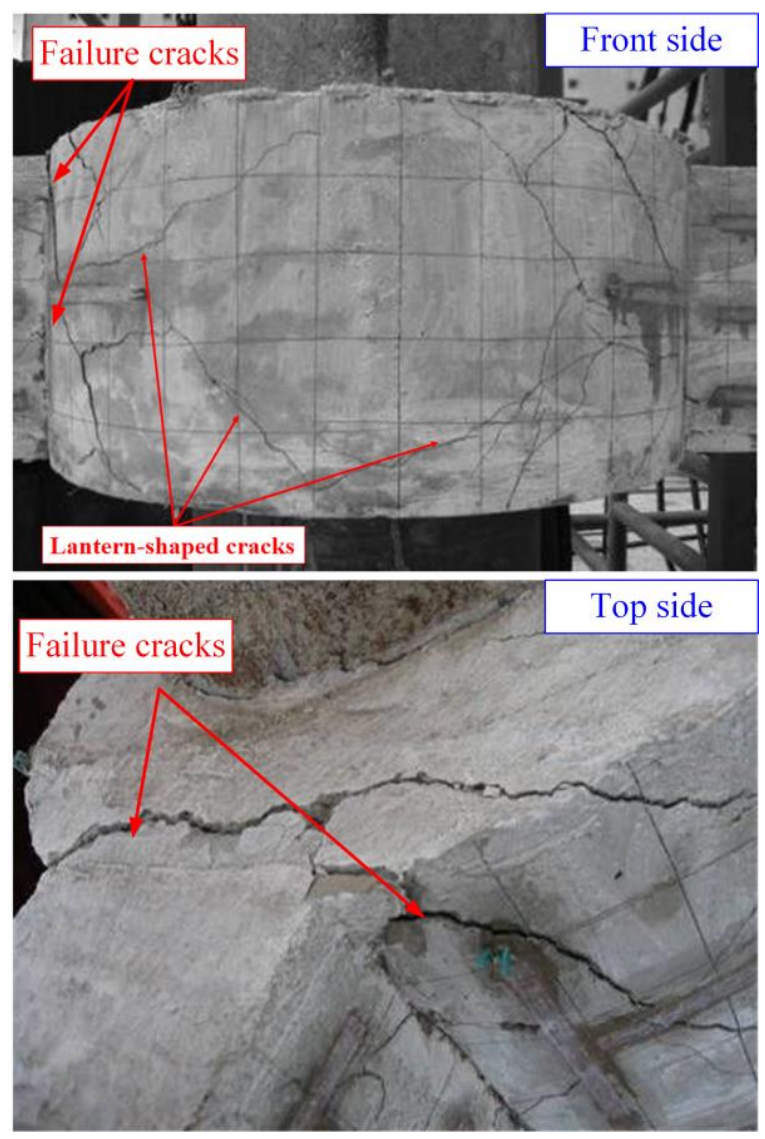

(a) Experimental test

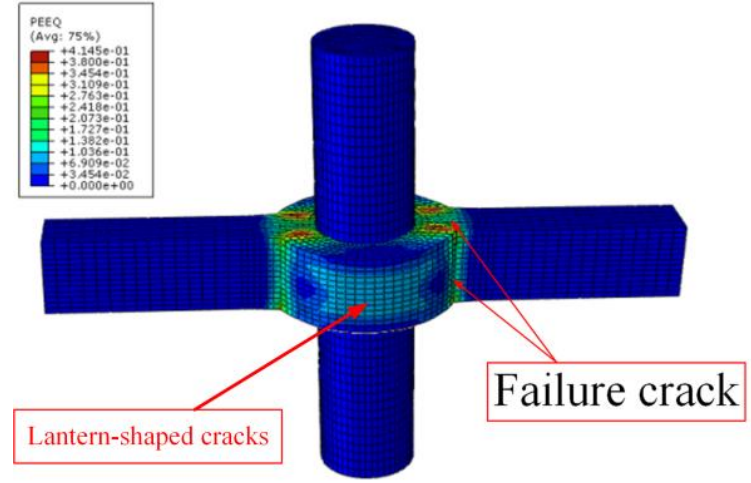

(b) Numerical simulation

Fig. 5 Comparison of simulated and experimental failure mode

\subsubsection{Failure modes}

Fig. 5 shows a comparison of simulated and tested failure mode. The failure mode of the ring-beam connection obtained in numerical simulation matched well with those in experimental tests, with concrete cracking formed at the ends of frame beam near the region of the ring beam. The ring-beam connection to the GCFST column failed due to the significant cracks in the region between ring beam and frame beam for both modeled and tested results. The lanternshaped cracks were shown in the side of ring beam for numerical model, which agreed well with the experimental observations. For the ring-beam connection, the GCFST column remained intact in both numerical simulation and experimental test. These observations indicated the adequate strength and stiffness of the ring-beam connection to resist seismic loads, which satisfies the design philosophy in the seismic code for buildings that "strong column and week beam, strong connection and week members" [22].

\subsubsection{Load-displacement curve and skeleton curve}

Fig. 6 illustrates a comparison of simulated and experimental load (P) displacement $(\Delta)$ curves for exterior and interior connections, where $P$ represents the load imposed at frame beam ends, and $\Delta$ represents vertical displacement at the frame beam ends. As shown in Fig. 6, the simulated curves matched acceptably with the experimental curves, with the similar strength degradation and stiffness reduction during the process of loading. However, the simulated curves were fuller than the experimental curves, with the pinching observations formed in the experimental curves. The difference in curve shape would be caused by the deficiency of selected concrete constitutive model in modeling the significant reinforcement-concrete bond slip behavior. Few research studies have been conducted to develop and evaluate the gangue concrete constitutive model under different loading condictions. As a result, a perfect concrete model was not located in the open literature.

Fig. 7 compares simulated and experimental skeleton curves for the interior and exterior ring-beam connections. Table 1 summarizes tested and simulated characteristic loads for each connection. As shown in Fig. 7 and Table 2, the simulated skeleton curves achieved an acceptable agreement with the experimental results with a slightly lower peak. The difference of the peak value between the numerical simulation and experimental tests was approximately $10 \%$. As indicated in relevant research studies [11, 23, 24], the difference between simulated and tested results up to $20 \%$ was acceptable for a complex FE model. This difference was attributed to the deficiency of concrete constitutive model and the Tie model selected to represent welding for each steel component. Overall, the developed model reasonably represented the failure mode of ring-beam connection under seismic loading and acceptably predicted the strength and stiffness degradation.

Table 2

Comparison of character loads and displacements

\begin{tabular}{ccccccc}
\hline Model & $\begin{array}{c}P_{0} \\
(\mathrm{kN})\end{array}$ & $\begin{array}{c}\Delta y \\
(\mathrm{~mm})\end{array}$ & $\begin{array}{c}P_{y} \\
(\mathrm{kN})\end{array}$ & $\begin{array}{c}\Delta_{\max } \\
(\mathrm{mm})\end{array}$ & $\begin{array}{c}P_{\max } \\
(\mathrm{kN})\end{array}$ & $\begin{array}{c}P_{u} \\
(\mathrm{~mm})\end{array}$ \\
\hline JH-E-B & 11 & 1.9 & 21 & 6.23 & 39 & 32.7 \\
JH-A-B & 12.10 & 1.83 & 19.02 & 5.93 & 44.15 & 37.52 \\
JH-E-Z & 13 & 2.1 & 24 & 6.37 & 49 & 42.6 \\
JH-A-Z & 12.45 & 2.02 & 23.38 & 5.95 & 47.72 & 40.56 \\
\hline
\end{tabular}




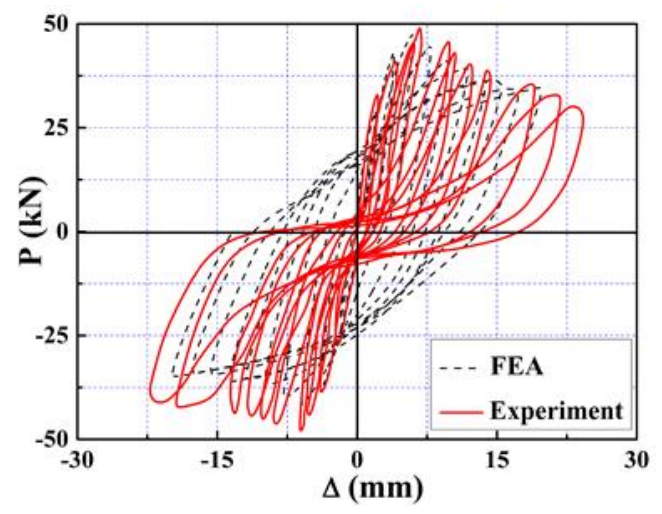

(a) Interior connection

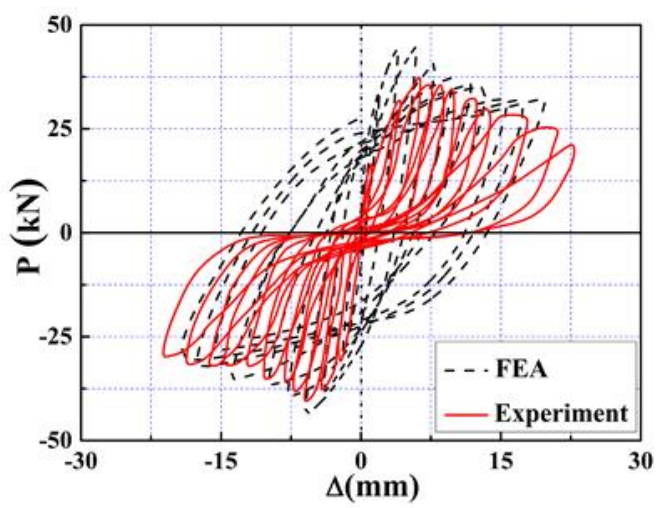

(b) Exterior connection

Fig. 6 Comparison of tested and simulated load-displacement curves

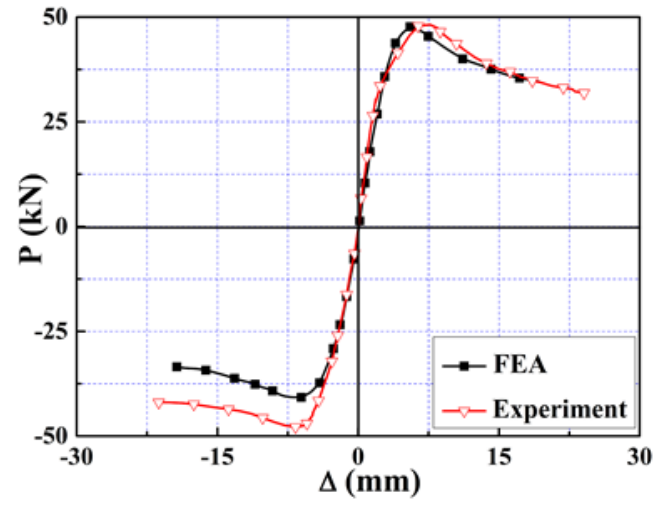

(a) Interior connection

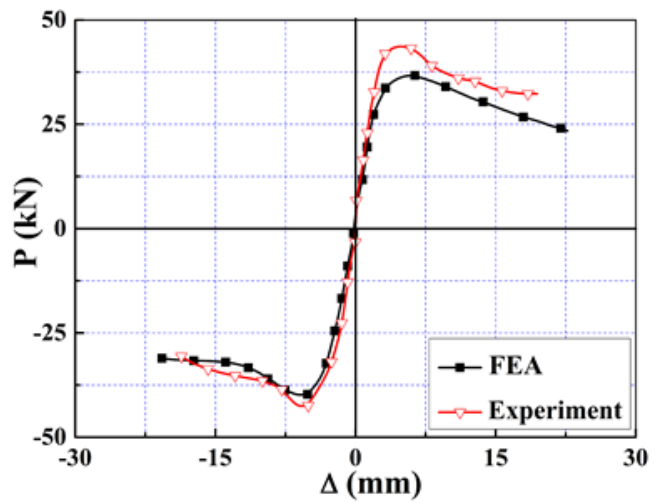

(b) Exterior connection

Fig. 7 Tested and simulated load-displacement skeleton curves

\section{Predicted behavior of ring-beam connection}

Fig. 8 shows the load-dipslacement curves of the ring-beam connection to CFST column when subjected to cyclic load. In this figure, four representative

points were defined to analyze the connection behavior at different phases. Point A indicates the appearance of first crack in the frame beam, with the bearing capacity defined as $P_{0}$. Point B represents the yielding of ring beam connection, and the corresponding connection bearing capacity was defined as $P_{y}$. As the load reaches the peak value, the ultimate bearing capacity of the ring-beam connection $\left(P_{\max }\right)$ is obtained in the curve, referenced as to Point C. Point D represents the load at connection failure $\left(P_{u}\right)$ when the load reduced to $85 \%$ of $P_{\max }$. The behavior of each component in the ring beam connection was analyzed in the following sections.

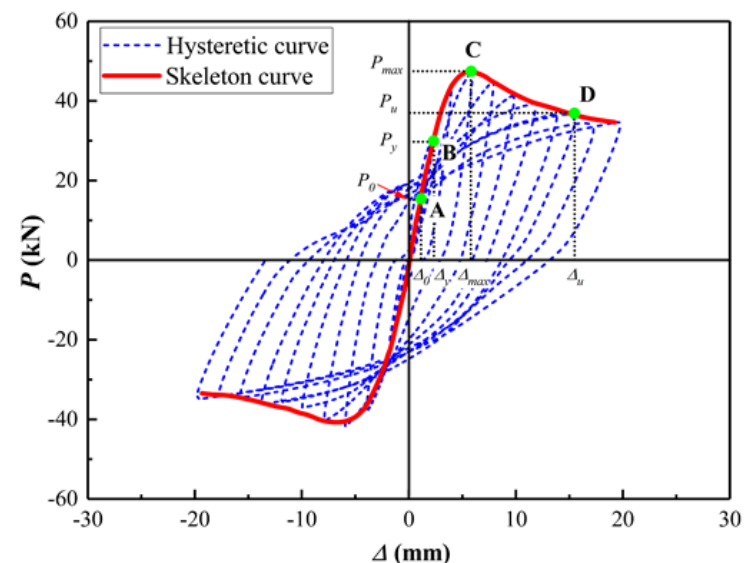

Fig. 8 Typical $P-\triangle$ curve for a connection to GCFST column

\subsection{GCFST column}

The GCFST column was subjected to bending moments created from the cyclic load at the ends of frame beams and an axial load at the column top. Fig. 9 depicts the stress of confined gangue concrete (S33, in MPa) in the GCFST column at each point, in which the stress is the concrete compressive stress along the normal direction. The compression region developed along the column height and the compressive stress increased with the increased cyclic load at the ends of frame beams, as shown in Fig. 9. Furthermore, the lateral deformation of the core concrete increased as the axial load was applied at the top, resulting in the increase of the steel tube confinement on the core gangue concrete. At point $\mathrm{C}$, the concrete compressive stress reached 24.1 MPa which approximates to $1.18 f_{c}$ '. This finding indicated that the steel tube confinement is beneficial to the increased strength of the concrete due to triaxial stress state. The accumulation of damage in the core gangue concrete resuted in the decrease in the concrete compressive stress after the point $\mathrm{C}$,

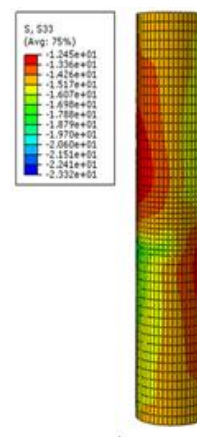

$\mathbf{A}$

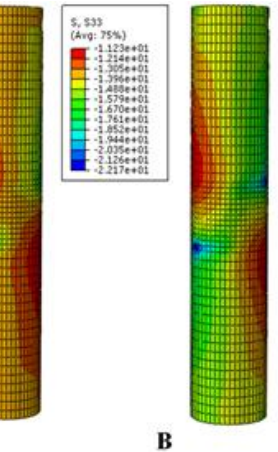

B

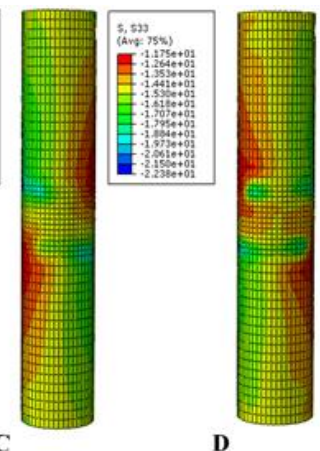

C

Fig. 9 Compressive stress of core gangue concrete

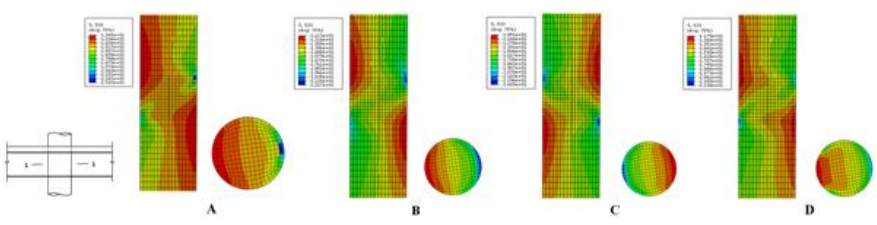

Fig. 10 Compressive stress in the connection zone

Fig. 10 plots cross-sectional stress distribution for the confined concrete in GCFST column at each point. It was observed that the neutral axis of the 
confined concrete shifted from the tensile region to the compressive region with the increase in the load. A diagonal compressive strut was developed for the center region of the ring beam connection, identifying that the confined concrete carried the shear stress and moment. The compressive strut extended as the average stress increased with the increased load. The maximum average stress of the compressive strut was obtained at the point $\mathrm{C}$. Then, the compressive strut continued expanding with the decreased average compressive stress due to the accumulated concrete damage after the point $\mathrm{C}$.

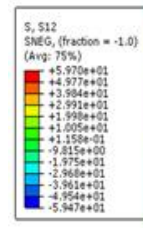

A

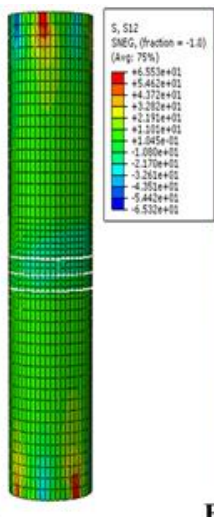

B
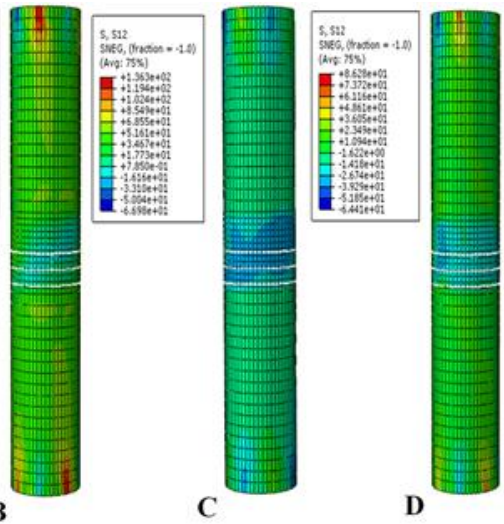

Fig. 11 Shear stress for steel tube

The steel tube shear stress (S12) in the GCFST column at each point is shown in Fig. 11, in which shear stress is used to examine the load-transferring mechanism for the composite connection. Fig. 12 plots the stress of shear ring along the perimeter at the point $\mathrm{C}$. The average stress of the tube increased and the stress zone in the connection region developed with the increase in the cyclic load. A diagonal stress zone was observed in the connection region at the point $\mathrm{C}$, and shear ring stress was lower than the steel yield strength in the elastic state. It can be observed that the shear ring was functioned to transfer the shear stress to the column which was the primary component to sustain the shear stress under cyclic loading.

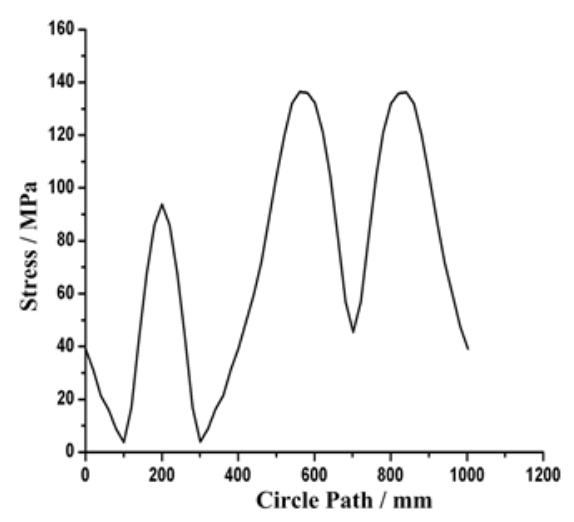

Fig. 12 Shear ring stress along perimeter at point $\mathrm{C}$

\section{2. $R G C$ beam}

Fig. 13 shows stress distribution (S11, in MPa) in RGC beam at the characteristic points along with the equivalent plastic strain shown in Fig. 14. In Fig. 14, the equivalent plastic strain represents the formation of concrete cracks in the beam. The compressive and tensile stresses were observed at the top and bottom sides of RGC beam close to GCFST column due to bending moment and compression load along the beam length at the point A. The initial crack was formed in the region between the ring beam and the frame beam at this point. As the cyclic load increased, the compression region developed along the beam length, and concrete cracks was shown to propagate along the beam depth. At the point $\mathrm{C}$, the lantern-shape cracks were formed in the side of ring beam with significant concrete cracks observed through the frame beam. At point $\mathrm{D}$, concrete cracks were extended to the ring beam, and this connection failed due to significant concrete cracks in the frame beam.

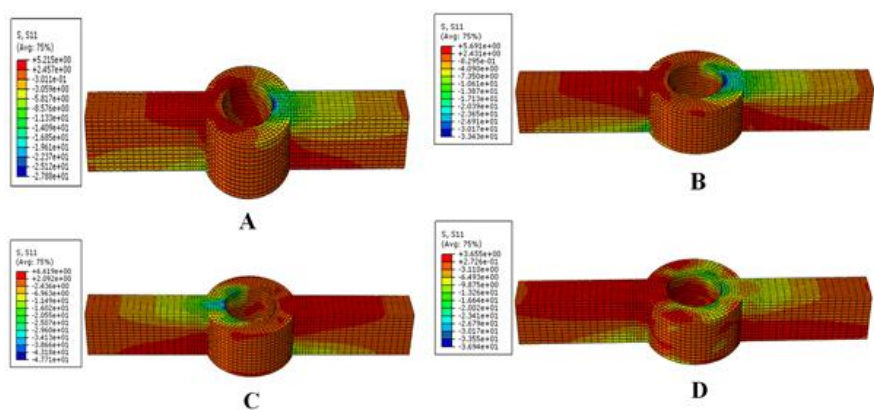

Fig. 13 Stress distribution (S11) in RGC beam

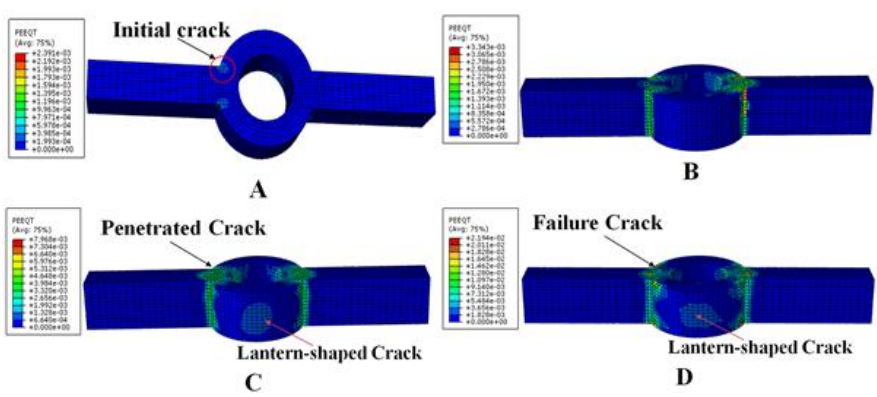

Fig. 14 Equivalent plastic strain distribution in RGC beam

Fig. 15 shows reinforcement stress in the RGC beam at the characteristic points. As shown in Fig. 15, the compressive and tensile stress in reinforcements was formed at the top and bottom sides of the frame RGC beams in the initial phase of loading. The increased cyclic load resulted in the increased stress in the reinforcements. As the cyclic load increased at the point B, the longitudinal reinforcements embedded in the frame beam were yielded with the yielding of circular reinforcements in the ring beam. This observation indicated the yielding of ring-beam connection. At point $\mathrm{C}$, the stress in the longitudinal and circular reinforcements further increased, while was still less than the reinforcement ultimate strength. The hoops in the region between the ring beam and frame beam were yielded during the loading.
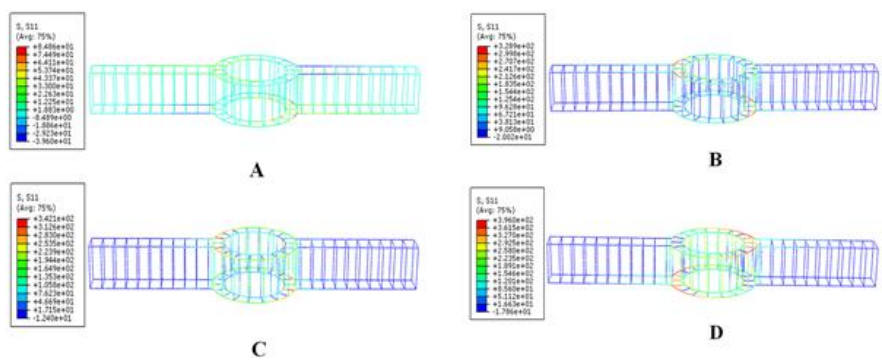

Fig. 15 Stress distribution of reinforcements in RGC beam

Based on the behaviors of structural components in this composite connection, the load transferring mechanism of the ring-beam connection was summarized as: The bending moment was produced on the ring beam and could be simplified as the compression and tension forces at the top and bottom side of the ring beam when the cyclic loads were applied at the ends of the frame beams. The compression force was transferred through the ring beam and sustained by the GCFST column, while the tension force was resisted by the circular reinforcement and hoop in the ring beam. In addition, shear forces formed in the frame beams were transferred to the GCFST column through three primary components, (i) shear ring welded in the tube was used to transfer shear forces through interaction forces between shear ring and steel tube; (ii) adhesive force between ring beam and steel tube also played an essential role in the shear transferring mechanism; and (iii) a diagonal strut was developed around the connection region to produce the significant friction force due to the extrusion of ring beam on the GCFST column.

\section{Parametric studies}

Parametric studies were performed that examined the influences of several 
design parameters on dynamic response of the ring beam connection when subjected to cyclic loads. The studied parameters include: (1) Material parameters: concrete compressive strength and steel yield strength; (2) Geometric parameters: steel ratio, GCFST column slenderness ratio, beam-tocolumn stiffness ratio, and width of ring beam; (3) Load parameters: axial load magnitude at the column top.

Effects of the studied parameters were evaluated by examining bending moment $(M)$ to rotation $(\theta)$ relationship of the beam and the initial stiffness of the connection. In this section, the skeleton curves for the bending moment to rotation relation were used to clearly examine the initial stiffness and the ultimate bearing capacity of the ring-beam connection. The initial stiffness of the ring-beam connection is determined as the secant stiffness corresponding to the $0.2 M_{u j}$ according to the research studies [25] for CFST member as shown in Eq. (3).

$K_{i}=\frac{0.2 M_{u j}}{\theta_{0.2}}$

where $K_{i}$ is the ring-beam connection initial stiffness; $M_{u j}$ represents the ultimate beading moment; and $\theta_{0.2}$ is the rotation that corresponds to $0.2 M_{u j}$. Fig. 16 illustrates the $M-\theta$ curves and resulting skeleton curves in the parametric studies for ring beam connection.

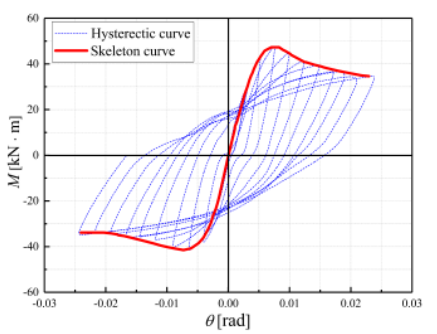

(a) JH-A-Z

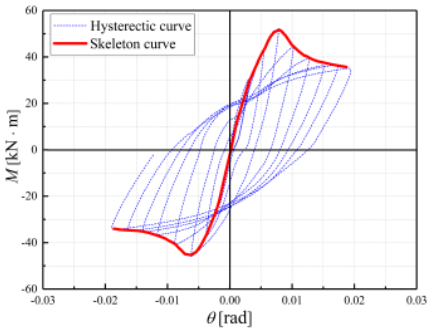

(c) $n=0.8$

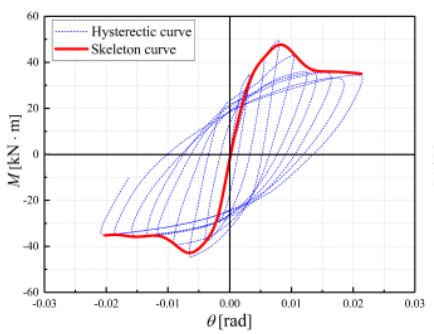

(e) $\alpha=0.106$

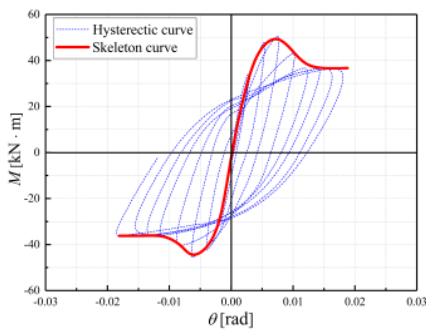

(g) $b_{0}=140 \mathrm{~mm}$

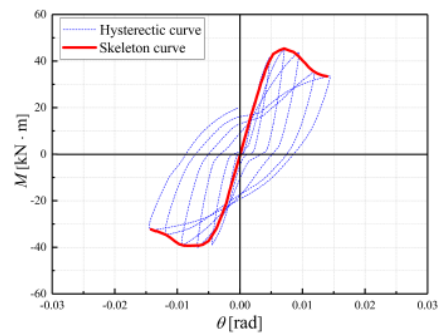

(b) $n=0.2$

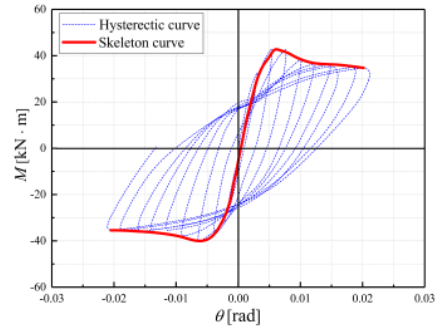

(d) $\alpha=0.056$

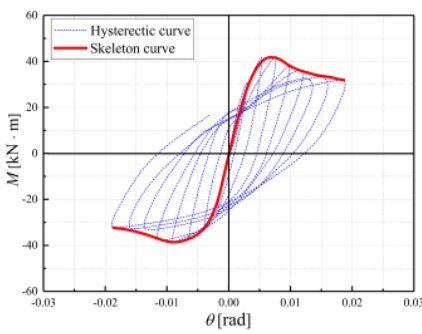

(f) $b_{0}=100 \mathrm{~mm}$

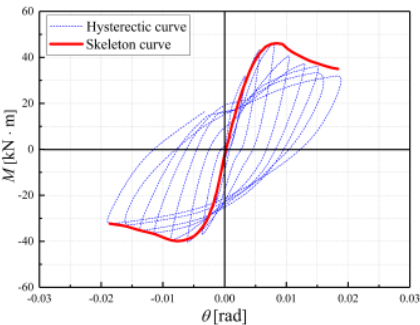

(h) $f_{c, c}^{\prime}=20 \mathrm{MPa}$

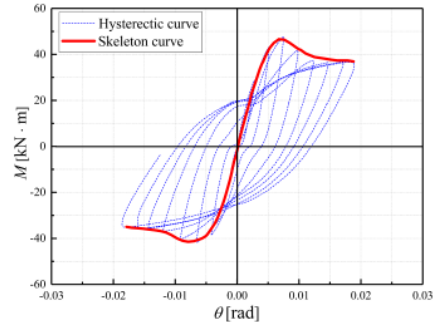

(i) $f_{c, c}^{\prime}=40 \mathrm{MPa}$

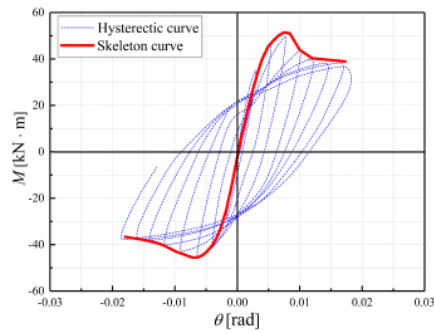

(k) $f_{c, b}^{\prime}=40 \mathrm{MPa}$

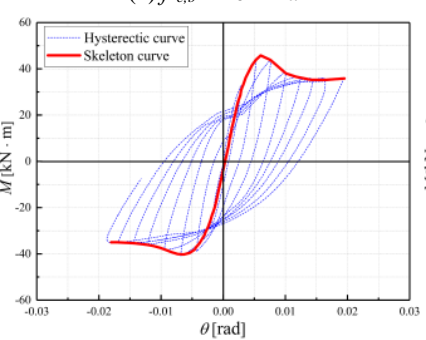

(m) $\lambda=49$

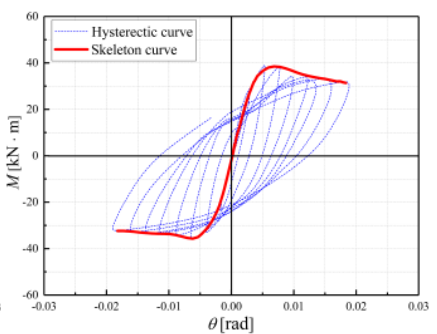

(j) $f_{c, b}^{\prime}=20 \mathrm{MPa}$

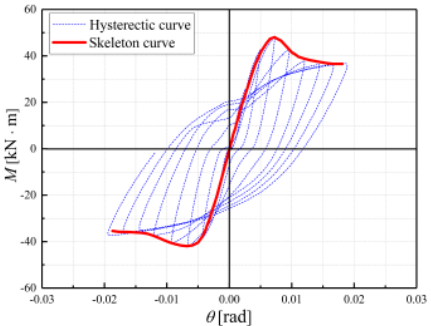

(1) $\lambda=25$

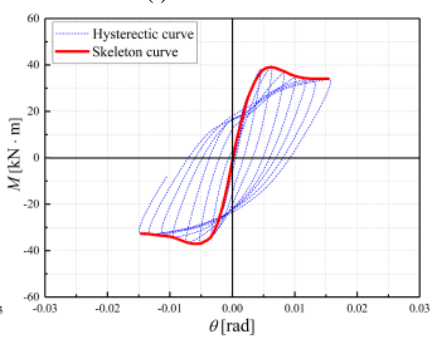

(n) $\mathrm{k}=0.711$

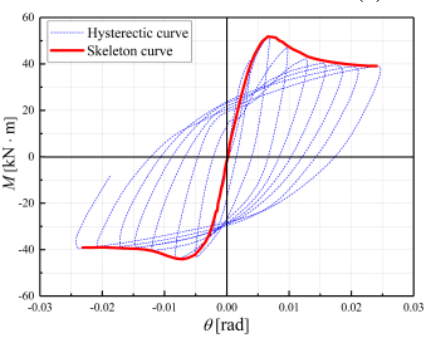

(p) $\mathrm{k}=1.066$

Fig. $16 M-\theta$ curves in parametric studies for ring beam connection

\subsection{Axial load ratio (n)}

In this section, three axial load ratios, including $0.2,0.6$, and 0.8 , were considered to apply the axial load at the column top. Fig. 17 illustrates influences of axial load ratio on the $M-\theta$ curves, with Fig. 18 on the connection initial stiffness. The axial load ratio affected the ring-beam connection flexural capacity, as shown in Fig.s 17 and 18. The increased axial load magnitude at the column top resulted in the increased flexural bearing capacity of the ring beam connection. The moment increased linearly with the rotation at the initial phase of loading. As the the axial load ratio increased, the ring-beam connection initial stiffness increased in an approximately linear relation. The connection stiffness at the hardening phase increased with the increased axial load ratio, and the connection would be failed earlier at a higher axial load. The increased axial load magnitude at the column top beneficially improved the column bending moment capacity and enhanced the ring-beam connection flexural capacity.

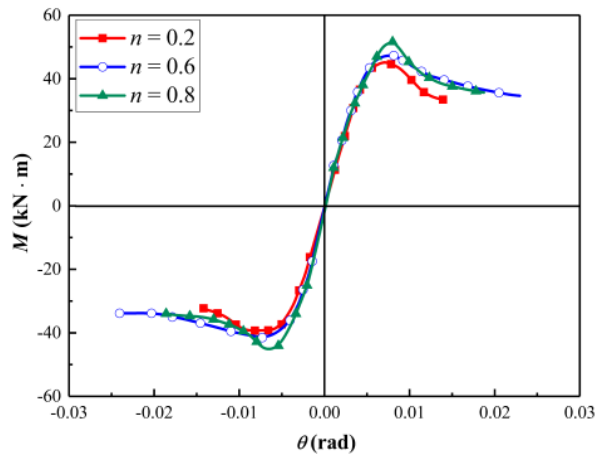

Fig. 17 Effects of $n$ on $M-\theta$ curve 


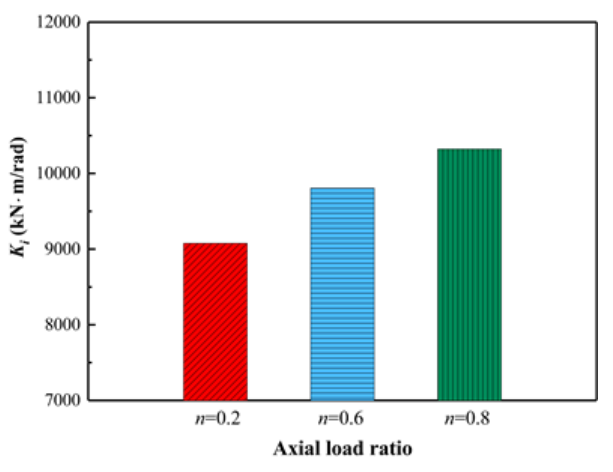

Fig. 18 Effects of $n$ on initial stiffness

\subsection{GCFST column steel ratio $(\alpha)$}

The steel ratio was varied by the change of steel tube thickness in this study. Three tube thicknesses were selected as $5 \mathrm{~mm}, 6 \mathrm{~mm}$, and $7 \mathrm{~mm}$. Fig. 19 illustrates effects of steel ratio on the $M-\theta$ relation, with Fig. 20 shown effects of steel ratio on the connection initial stiffness. The stiffness and flexural capacity of the ring-beam connection increased with the increased steel ratio of the GCFST column. The maximum flexural capacity was improved by $20 \%$ when the steel ratio increased from 0.056 to 0.078 , while the flexural capacity increased by $5 \%$ with the increase in the steel ratio from 0.078 to 0.106 . Similarly, the initial stiffness of the connection increased by approximately $25 \%$ as the steel ratio increased from 0.056 to 0.106 . After the ultimate flexural capacity, the decrease of the flexural bearing capacity is aggravated with the increase of steel ratio. The increase in the connection flexural capacity was not as prominent as that observed from 0.056 to 0.078 in terms of ultimate flexural capacity and initial stiffness when the steel ratio increased from 0.106 to 0.078 , A limit to the connection capacity improvement exists as the column steel ratio increaes. Overall, the steel ratio of GCFST column significantly influenced the bearing capacity of the ring beam connection.

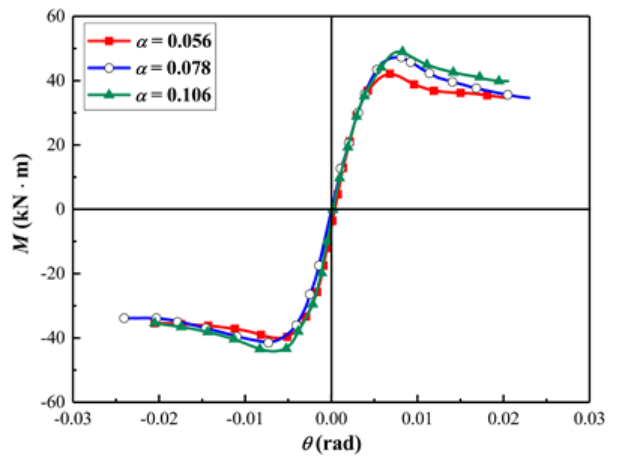

Fig. 19 Effects of $\alpha$ on $M-\theta$ curve

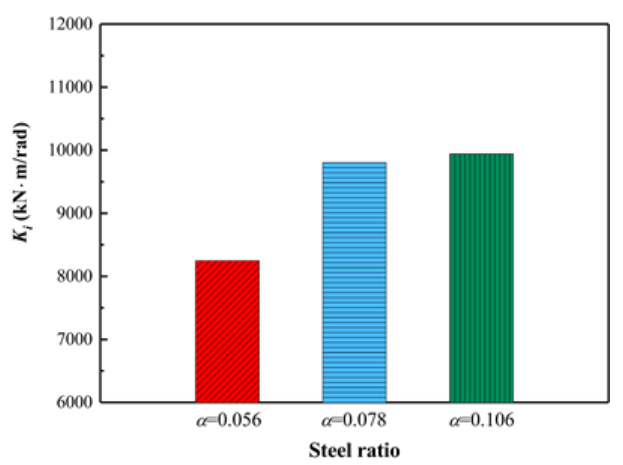

Fig. 20 Effects of $\alpha$ on initial stiffness

\subsection{Ring beam width $\left(b_{0}\right)$}

The ring beam width is expected to influence the ability of the ring beam to transfer shear force and bending moment to the GCFST column. Three widths $(140 \mathrm{~mm}, 120 \mathrm{~mm}$, and $100 \mathrm{~mm})$ were used to investigate its effect on connection behavior. Fig. 21 illustrates effects of ring beam width on the $M-\theta$ relation, with Fig. 22 shown effects of ring beam width on the connection initial stiffness. As shown in Fig. 21, the ring-beam connection flexural capacity was enhanced with an increase in ring beam width. The ultimate flexural bearing capacity for $b_{0}=140 \mathrm{~mm}$ was $18 \%$ and $5 \%$ higher than those for the connection with $b_{0}=100 \mathrm{~mm}$ and $120 \mathrm{~mm}$, respectively. It was observed from Fig. 22 that, the influence of ring beam width on the initial stiffness of the connection was insignificant with a similar value of $10000 \mathrm{kN} \cdot \mathrm{m} \cdot \mathrm{rad}^{-1}$ obtained for three connections. Increasing ring beam width was beneficial to the connection capacity to sustain and transfer the bending moments produced from the cyclic load at the frame beams.

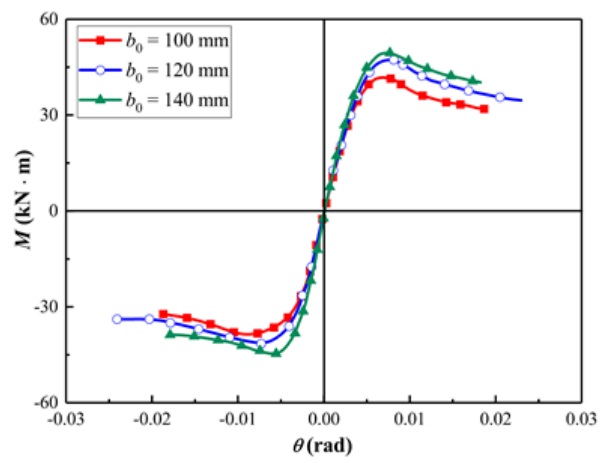

Fig. 21 Effects of $b_{0}$ on $M-\theta$ curve

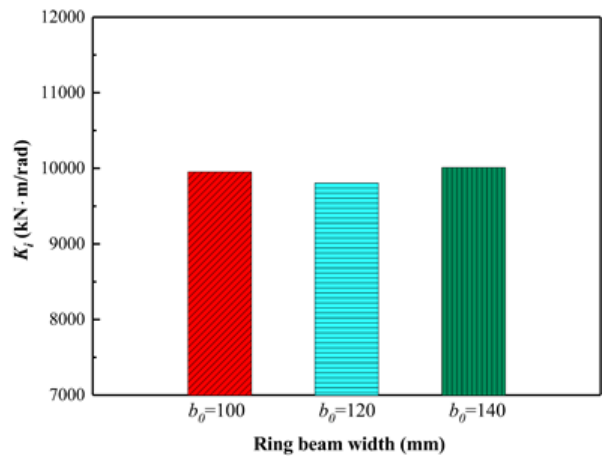

Fig. 22 Effects of $b_{0}$ on initial stiffness

\subsection{Confined concrete compressive strength $\left(f_{c, c}^{\prime}\right)$}

Three compressive strengths of cofined concrete, involving $20 \mathrm{MPa}, 30$ $\mathrm{MPa}$, and $40 \mathrm{MPa}$, were selected to analyze its effects on the connection behavior. Fig. 23 illustrates effects of concrete compressive strength in GCFST column on the $M-\theta$ relation, with Fig. 24 shown on the connection initial stiffness. As shown in Figs. 23 and 24, the confined concrete compressive strength in GCFST column had an insignificant influence on the initial stiffness and flexural capacity of the ring-beam connection. This finding was attributed to the design principle used for the ring-beam connection in this study that "strong column and weak beam" and the intact column during the loading.

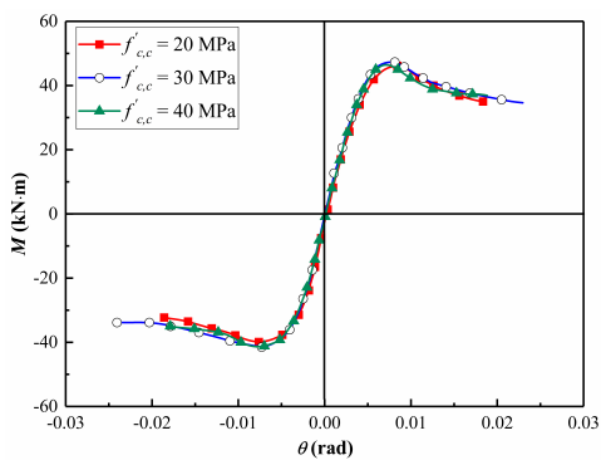

Fig. 23 Effects of $f_{c, c}^{\prime}$ on $M-\theta$ curve 


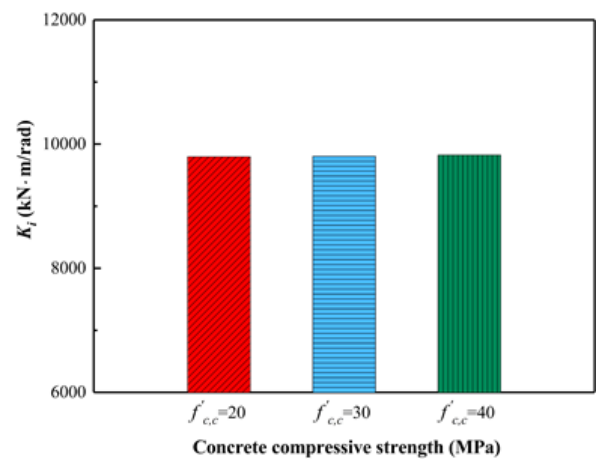

Fig. 24 Effects of $f_{c, c}^{\prime}$ on initial stiffness

\subsection{Concrete compressive strength in frame beam $\left(f_{c, b}^{\prime}\right)$}

Similarly, effects of concrete compressive strength in the frame beam were examined in this section. The concrete strength included $20 \mathrm{MPa}, 30 \mathrm{MPa}$, and $40 \mathrm{MPa}$. Fig. 25 illustrates effects of concrete compressive strength in frame beam on the M- $\theta$ relation, with Fig. 26 shown on the connection initial stiffness. It was observed that, the increased concrete compressive strength in the frame beam resulted in the increased the ring-beam connection flexural capacity. The maximum flexural capacity of the ring-beam connection for $f_{c, b}^{\prime}=40 \mathrm{MPa}$ was 1.1 and 1.4 times larger than those for the connection for $f_{c, b}^{\prime}=30 \mathrm{MPa}$ and 20 $\mathrm{MPa}$, respectively. At the initial loading phase, the concrete compressive strength in frame beam had an insignificant effect on the behavior of the ringbeam connection with similar initial stiffness of $10000 \mathrm{kN} \cdot \mathrm{m} \cdot \mathrm{rad}^{-1}$ obtained for three studied connections due to the elastic behavior exhibited in the connections. Therefore, an increase in the concrete compressive strength in the frame beam was advantageous to the ring-beam connection flexural capacity to resist rotation, which improves connection behavior after the occurrence of cracks.

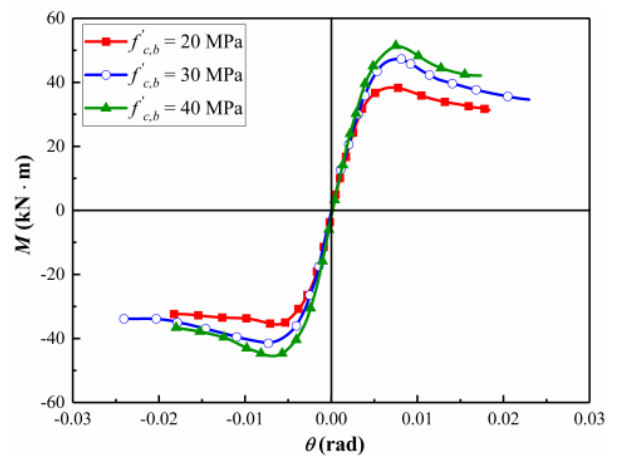

Fig. 25 Effects of $f_{c, b}^{\prime}$ on $M-\theta$ curve

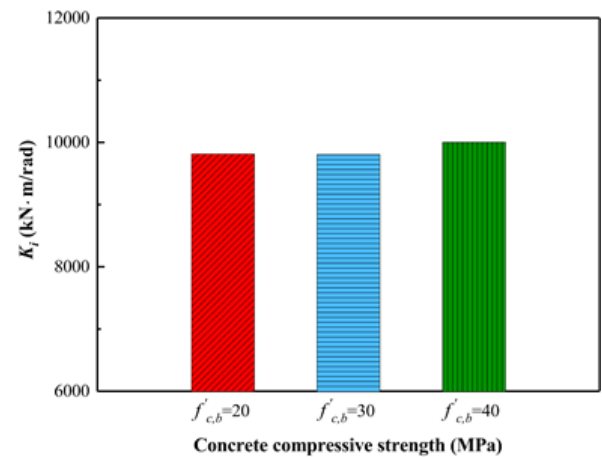

Fig. 26 Effect of $f_{c, b}^{\prime}$ on initial stiffness

\subsection{GCFST column slenderness ratio $(\lambda)$}

GCFST column slenderness ratio is expected to change the deformation pattern of the connection. In this study, the GCFST column slenderness ratio was varied with the change of column height. The studied column height included $1000 \mathrm{~mm}, 1500 \mathrm{~mm}$, and $2000 \mathrm{~mm}$, which produced the column slenderness ratios of 25, 36, and 49. Fig. 27 illustrates effects of GCFST column slenderness ratio on the M- $\theta$ relation, with Fig. 28 shown on the connection initial stiffness. The effect of the GCFST column slenderness ratio on the flexural capacity and initial stiffness of the ring-beam connection was insignificant with almost identical ultimate flexural capacity and initial stiffness, as shown in Figs. 27 and 28. In the design principle for the connection, the strength of the GCFST column should be higher than the frame beam strength, and the column failure was avoided in this study. Therefore, the slenderness of the GCFST column insignificantly influenced the behavior of the ring beam connection.

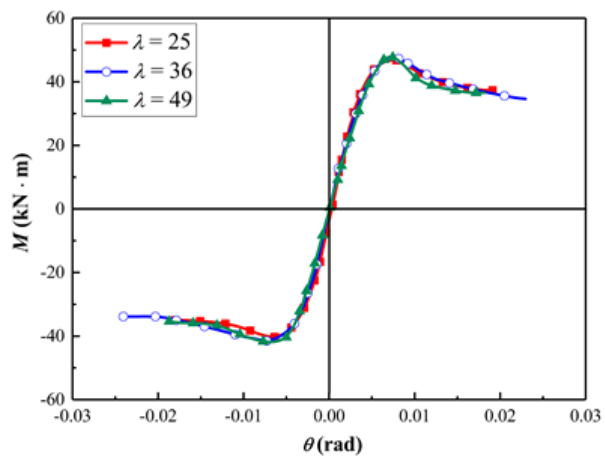

Fig. 27 Effects of $\lambda$ on $M-\theta$ curve

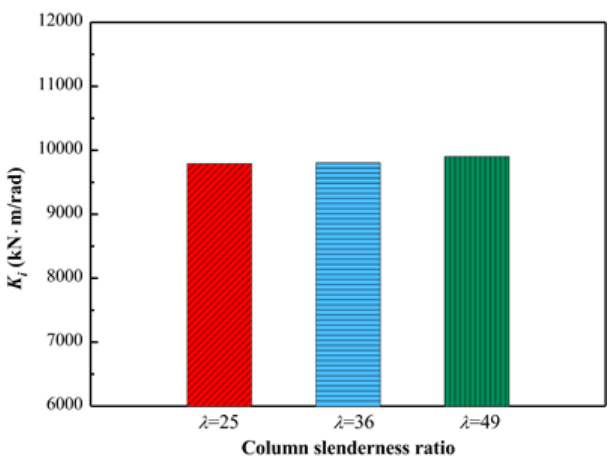

Fig. 28 Effects of $\lambda$ on initial stiffness

\subsection{Beam-to-column stiffness ratio $(k)$}

The beam-to-column stiffness ratio is expected to affect the development and location of plastic hinge in the RGC frame beam. The beam-to-column stiffness ratio was changed by varying the length of frame beam in this study, Three beam lengths of $800 \mathrm{~mm}, 1000 \mathrm{~mm}$, and $1200 \mathrm{~mm}$ were selected. Fig. 29 illustrates effects of column-beam stiffness ratio on the M- $\theta$ relation, with Fig. 30 shown on the connection initial stiffness. As shown in Fig. 29 and Fig. 30 the flexural capacity of the ring beam connection was enhanced as the beam-tocolumn stiffness ratio increased. The ultimate flexural capacity increased by about $33 \%$ with the increase of the beam-to-column stiffness ratio from 0.711 to 0.853 , while the connection capacity increased by approximately $5 \%$ as $k$ increased from 0.853 to 1.066 . The ring-beam connection stiffness was significantly improved with the increased beam-to-column stiffness ratio. Connection initial stiffness for $k=1.066$ was $38 \%$ higher than that for the connection with $k=0.711$. This finding was also attributed to the design principle for the ring-beam connection in this study that "strong column and weak beam".

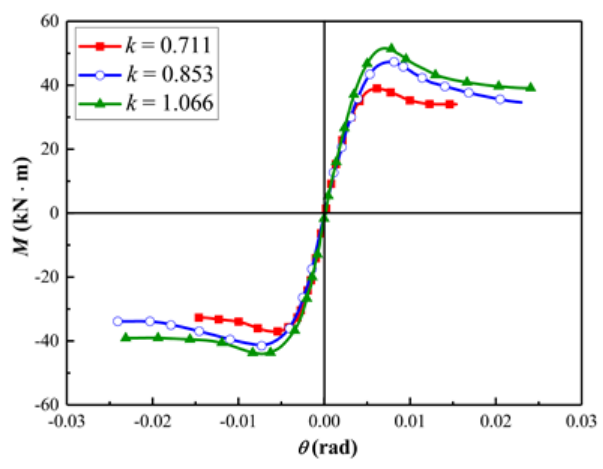

Fig. 29 Effects of $k$ on $M-\theta$ curve 


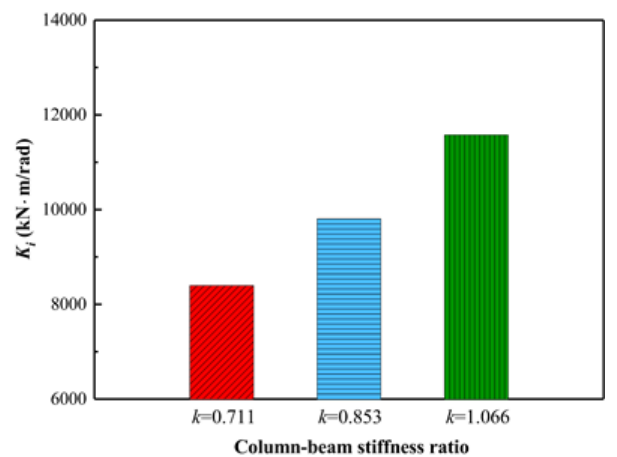

Fig. 30 Effects of $k$ on initial stiffness

\section{Conclusions}

This paper numerically examined cyclic loaded dynamic response of a ringbeam connection between GCFST column and RGC beams. Detailed 3D, nonlinear, numerical models were developed using ABAQUS. Two specimens including an exterior connection and an interior connection were used to validate the feasibility of developed connection model with the experimental results. The behavior of the ring beam connection was examined to identify the force transferring mechanism and failure modes when subjected to the cyclic loads at frame beam ends. Extensive parametric studies were performed to assess the effects of critical design parameters on the connection behavior. The following conclusions were drawn in this paper:

(1) Finite element models were acceptably validated against the full-scale tests. Validation study demonstrated the ability of the developed model to

\section{References}

[1] Zhao X.L., Han L.H., Lu H. Concrete-Filled Tubular Members and Connections, Spon Press New York, 2010.

[2] Li G.C., Fang C., Zhao X., An Y., Liu Y. "Cyclic Behavior of Rebar-Penetrated Connection between Gangue Concrete Filled Steel Tubular Column and Reinforced Gangue Concrete Beam", Advanced Steel Construction, 115, 54-72, 2015

[3] Li G.C., Fang C., An Y.W., Zhao X. "Seismic Behavior of Rebar-Penetrated Joint between GCFST Column and RGC Beam", Steel and Composite Structures, 19, 547-67, 2015

[4] Xiao J.Z., Li W.G., Fan Y.H., Huang X. "An Overview of Study on Recycled Aggregate Concrete in China (1996-2011)", Construction and Building Materials, 31, 364-83, 2012

[5] Guo J.M. Experimental Research on Performances of Concrete with Coal Gangue. 2011 International Conference on Materials for Renewable Energy\&Environment2011. p. 198891.

[6] Li G.C. "Strength and Lateral Deformation Coefficient of Gangue Concrete Restrained by Steel Tube", Harbin Jianzhu Daxue Xuebao/Journal of the Harbin University of Civil Engineering and Architecture, 35, 20-3, 2002

[7] Nelson A.J., Rakau O., Dörrenberg P. "Green Buildings: A Niche Becomes Mainstream", Deutsche Bank Research, 2010

[8] Li W., Han L.-H. "Seismic performance of CFST column to steel beam joints with RC slab: Analysis", Journal of Constructional Steel Research, 67, 127-39, 2011

[9] Pucinotti R., Bursi O., Demonceau J.F. "Post-Earthquake Fire and Seismic Performance of Welded Steel-Concrete Composite Beam-to-Column Joints", Journal of constructional steel research, 67, 1358-75, 2011

[10] Chen Q.J., Cai J., Bradford M.A., Liu X.P., Zuo Z.L. "Seismic Behaviour of a Through-Beam Connection between Concrete-Filled Steel Tubular Columns and Reinforced Concrete Beams", Engineering Structures, 80, 24-39, 2014

[11] Ding F.X., Yin G.A., Wang L.P., Hu D., Chen G.Q. "Seismic performance of a non-throughcore concrete between concrete-filled steel tubular columns and reinforced concrete beams", Thin-Walled Structures, 110, 14-26, 2017

[12] Yu T., Teng J., Wong Y., Dong S. "Finite Element Modeling of Confined Concrete-II: PlasticDamage Model", Engineering Structures, 32, 680-91, 2010 reasonably predict failure modes and cyclic-loaded behaviors of the ring-beam connection.

(2) Failure of the ring-beam connection was due to significant concrete cracking in the frame beam connected to the ring beam with no obvious damage occurred in the GCFST column. This observation satisfied the seismic design principle selected for the ring beam connection, and the design principle requires "strong column and weak beam" in the design code.

(3) Stress distribution analysis indicated that, when cyclic loads were imposed in the frame beam ends, bending moment was transferred by the ring beam and sustained by the GCFST column, while shear forces was transferred through the shear ring and resisted by the GCFST column and adhesive force between ring beam and tube. The cyclic load resulted in the development of a diagonal compressive strut in the region of ring-beam connection.

(4) Parametric studies indicated that GCFST column steel ratio, axial load ratio, beam-to-column stiffness ratio, and concrete compressive strength of the frame beam significantly influenced the initial stiffness and flexural capacity of the ring-beam connection under cyclic loading. Due to seismic design principle, the confined concrete compressive strength and GCFST column slenderness ratio had insignificant effects on the performance and dynamic response of the ring-beam connection.

\section{Acknowledge}

This project was supported by Natural Science Foundation of Jiangsu Province (BK20200996), Technology Program of Ministry of Housing and Urban-Rural Development (2011-k3-23), Liaoning Talents Program (LR2011014), University innovation team of Liaoning Province (LT2014012), and China Postdoctoral Science Foundation (2020M681566).

[13] Fu Z.Q., Ji B.H., Lv L., Zhou W.J. "Behavior of Lightweight Aggregate Concrete Filled Steel Tubular Slender Columns under Axial Compression", Advanced Steel Construction, 7, 144 56,2011

[14] Zhang J.W., Cao S.Y. "Research on the Stress-Strain Curves of Structural Lightweight Aggregate Concrete", Building Science, 24, 83-5, 2009

[15] Sorenson H.K. "ABAQUS Version 6.10: Theory Manual, Users' Manual, Verification Manual and Example Problems Manual", Hibbitt, Karlson, Sorenson Inc USA, 2011

[16] Oehlers D.J., Bradford M.A. Composite Steel and Concrete Structures: Fundamental Behaviour: Fundamental Behaviour, Elsevier, 2013.

[17] Boger R.K. Non-monotonic Strain Hardening and Its Constitutive Representation: The Ohio State University, 2006

[18] Yoshida F., Uemori T. "A Model of Large-Strain Cyclic Plasticity Describing the Bauschinger Effect and Workhardening Stagnation", International Journal of Plasticity, 18, $661-86,2002$

[19] Lu X.Z., Ye L.P., Miu Z.W. Static-Plastic Analysis on Seismic Performance of Structures. Beijing: China, Building Industry Press, 2009.

[20] Zhang Y.F., Zhao J.H., Yuan W.F. "Study on Compressive Bearing Capacity of ConcreteFilled Square Steel Tube Column Reinforced by Circular Steel Tube Inside", Journal of Civil Engineering and Management, 19, 787-95, 2013

[21] CECS28-2012. Technical Specification for Concrete-Filled Steel Tubular Structures. Beijing, China2013.

[22] GB50011-2010. Code for Seismic Design of Buildings. Beijing: China Architecture \&Building Press, 2010

[23] Han L.H., Li W. "Seismic Performance of CFST Column to Steel Beam Joint with RC Slab: Experiments", Journal of Constructional Steel Research, 66, 1374-86, 2010

[24] Transportation Research Board. Procedures for Verification and Validation of Computer Simulations Used for Roadside Safety Applications. Washington, DC, The National Academie Press, 2011.

[25] Han L.H. Concrete-Filled Steel Tubular Structure: Theory and Practice. Science Press, Beijing, 2017. 